\title{
Experience Design Driving Design Innovation of Traditional Redwood Furniture
}

\author{
Sheng Chuanxin \\ School of Packaging and printing \\ Zhongshan Torch Polytechnic \\ ZhongShan, CHINA \\ 402053907@qq.com
}

\begin{abstract}
In order to solve the problem about the design innovation of traditional redwood furniture. This paper introduces the development of traditional Chinese redwood furniture and also analyzes the relationship between experience design and traditional Chinese redwood furniture design innovation. It attempts to explore design innovation path from three aspects which include establishing interaction: human furniture - human interaction, establishing scenario: furniture space - culture experience, describing identify: life - meaning emotional experience. Experience design can exceed the user's expected value, closer to the needs of people and the market. The experience design will make new breakthroughs and market opportunities for the traditional redwood furniture industry, such as intelligent experience, green experience, cultural experience, human experience and brand experience.
\end{abstract}

Keywords-Redwood furniture; Experience; Experience design; Design innovation

\section{INTRODUCTION}

Because of its unique aesthetic value, exquisite material technology and practical material functions, the redwood furniture has been paid much attention, appreciation, experience, purchase and even promotion by everybody. People whose living space with redwood furniture has always been the focus of attention and praise, it seems that redwood furniture has close relationship for high quality life and cultural taste. However, looking at contemporary redwood furniture products, brands and service experiences, I found that there are many areas where designers and the community should think about together. For example, the terrible waste for a large number of redwood raw materials, whether it just meet a few consumers' exaggerated mind and show off the "redwood complex"? Redwood furniture design if really come true the design principle for "user-centered"? How long it will reach to redwood furniture manufacturing in 2025? For these issues above, how to design redwood furniture which full of humane care and touch users' minds, and pay attention to the sustainable development of ecology while improving the market competitiveness of redwood furniture products. It is the duty of the furniture designers in the current society.

\section{The ANALYsis ON THE PRESENT SituAtion OF CHINESE REDWOOD FURNITURE}

Traditional Chinese redwood furniture is originated in the 1970s. After more than 30 years of development and accumulation, the redwood furniture industry has developed into a large-scale, specialized, scientific and modern industrial cluster. Such as Da Cong Town, which is located in the Zhongshan City, Guangdong Province, has the title for "Chinese redwood furniture production town" and "Chinese redwood carving art town". The analysis and research on the design, manufacture, produce and sales of traditional Chinese redwood furniture were conducted through the comprehensive study of enterprise field investigation, online literature research and consumer questionnaire survey of redwood furniture stores [1]. From the perspective of the enterprises, there is not enough capability of independent innovation, the design and development mechanism is not perfect, and the reserve of technical personnel is not enough. Most furniture companies do not have design departments, blindly follow the trend of imitation, lack of thorough cultural understanding and interpretation of traditional classical furniture [2]. In addition, inadequate irrigation and cultivation for Industry-UniversityResearch Collaboration, also affect the output of new concepts, new ideas, new programs and new strategies. Second, from the social point of view, under the booming development of redwood furniture industry, it also consumes a lot of natural resources, most enterprises did not establish the green responsibility standards and activism, the designers study the furniture products without sustainable perspective. In recent years, with the skyrocketing prices of imported raw materials, labor wages have also risen faster and the profit margin of enterprises has naturally been compressed. Therefore, enterprises should consider using very few resource costs to exchange the higher profits and increase their position in the global value chain. Third, from the user's point of view, the aesthetic needs and functional requirements of modern consumers for redwood furniture have changed significantly from the previous ones. In particular, the new middle-income class who is 25 to 40 years old, that is, potential consumers in the future, how to grasp this kind of group's consumption characteristics, demand-driven and decision-making behaviors and create a unique attractive redwood cultural experience is becoming a new proposition for redwood furniture. 


\section{EXPERIENCE DESIGN AND CHINESE TRADITIONAL REDWOOD FURNITURE DESIGN INNOVATION}

\section{A. Experience Design: Based on the user's participation and overall feeling}

The word "experience" in "Ci Hai" is interpreted as "experience in person and actual feeling", emphasizing the consumers' personal consumption and experience of the process [3]. Nathan Shedroff defined the experience design as "integrating consumers' participation into the design, using the 'service' as the stage by enterprises, the product as the 'props' and the environment as the 'setting', which will make the consumers feel better experience in the commercial activities "[4]. Thus, the experience design innovation broke through the traditional industrial design innovation, so the user will be the centre of design innovation instead of the enterprises and products. Consumers become the participation in the design practice rather than the previous passive and accepted role. Secondly, consumers can feel the unique experience of products, systems and services throughout the entire consumer process. As a set of mature design theory system, experience design is widely used in the design and development of innovative products from home and abroad. However, this theory which is originated from the western design theory, how to make it better practice in the Oriental philosophy and aesthetic system for redwood furniture? Based on the above understanding and analysis of the meaning for experience, it is not difficult to find that there are too many similarities between "experience" and Chinese character "PIN". "As a verb, "PIN" contains the meanings of discrimination, assessment, analysis and sentiment. But for "experience", it includes the overall feeling process of induction (enhancement of familiarity), adaptation period (dependence of function), and identification period (attachment of emotion) from the perspective of time dimension [5]. The experience process and result is more perfect compared with "PIN". "Experience" not only emphasizes the user's design participation from the space dimension, but also attaches great importance to the enterprise initiative construction and creation.

\section{B. Redwood furniture experience: beyond the expectations of consumers return value}

The redwood furniture business should play the role of planner and creator for experience, not just providing redwood furniture products or services that are natural, simple, elegant, subtle and introverted but provide a deep interaction between furniture and people, with peace of mind and pleasure channel experience and valuable brand synergy experience. The tradeoff between design costs and benefits (Lidwell \& William, 2010), the redwood furniture experience is not just about fulfilling the users' ideas, but obtaining more subjective feeling reward at less cost, that is, the value return that exceeds the expectations of consumers [5].

\section{1) Interaction with people}

Redwood furniture and human interaction experience is mainly reflected in the modern ergonomics and functional realization of the aesthetics, this aesthetic feature is based on the comfort and practicality, and in a gentle form, delicate materials, quaint color and ingenious structure to display. In the process of human interaction, consumers can feel the beauty of the external form of furniture, such as proportions, lines, colors, texture, rhythm and many other elements. Constructed furniture reflects the square and circle, curved and straight, simple and complex, virtual and real, the priority and urgency, texture and tension. It can also cause consumer instinct thinking and unlimited associations. In addition, the functional expansion of furniture and operation of innovative design can also bring consumers' enjoyable experience.

\section{2) Channel experience}

Channel experience means the experience of the various media of contact between the enterprises and the user. In the era of "Internet Plus" consumer demand upgrade, users have become more enriched and stereoscopic in their approach to redwood furniture, changing from a single store retail experience to a more diversified and flat full-consumption channel experience. Virtual shopping guide, robot service, online shopping mall sales, mobile terminal sales and these experiences are gradually emerging, and it brings people more faster and worry-free service; Secondly, with the popularity of smart technologies and people's unremitting pursuit for quality of life, personalized and customization for whole household, and this kind of sales experience model also came into being[6]. In general, redwood furniture enterprises need to create a channel experience that meets the expectations of the target users, but also highlight the redwood furniture's feature and display consistency and interconnection of the brand's vision. For example, we can learn from the sales channels from SPZP, using the virtual product design method to strengthen the terminal users' experience, and provide the accuracy and effectiveness of the products through door-to-door ruler and design for free, in order to meet the personalized needs in the customer value chain [7].

\section{3) Brand experience}

Brand experience refers to the formation of a holistic impression and experience perception in the minds of consumers through the shaping of brand values, cultural concepts, idea philosophy and spiritual connotation, as well as the continuous delivery of the essence of brand mood. Richard Branson, the CEO of Virgin Group he said: "The brand experience is the result of ongoing behavior that requires time and life to develop, maintain and manage." Hans Wagner, the Nordic furniture designer, devoted his life to the design of wooden furniture, with his serious process design specifications and the possibility of breaking through the materials, and his craftsmanship made great achievements for "personal brand" in the furniture design filed. So regardless of enterprise's brand or designer's "personal brand", and brand experience has the characteristics of identification, continuity and effectiveness. BANMOO furniture follows the life philosophy of "take a half and gain more", expresses Chinese craftsmen have the calm and peaceful attitude in pursuit of furniture detail precision, and is related to oriental aesthetics 
for "everything is born from have, have is from nothing", redwood furniture stands out from all the furniture brands, giving people a cutting-edge, modest, calm and true brand experience, beyond the old, tedious and gorgeous overall impression of redwood furniture.

\section{The Design And InNOVATION Method OF CHINESE TRADITIONAL REDWOOD FURNITURE EXPERIENCE}

Experience design has the characteristics of metaphysical, complex, vague, non-quantifiable and qualitative. How to clearly grasp the variables and principles, and make redwood furniture experience becomes universal and perceptive ?In addition to analyze the experience concept of redwood furniture and its components, it is also necessary to use anthropology, sociology and psychology, these interdisciplinary perspectives to conduct research on the path of innovation for experience design.

\section{A. Establishing interaction: human - furniture - human interaction}

By creating opportunities for sharing, participating and interaction, designers create an interactive experience with redwood furniture [8]. Establishing this interactive experience requires that the furniture's functional parts have good feedback with the person's behavior, so it will make the relationship between control and effectiveness becomes predictable. For example, deal with furniture surface material and process, to form a tactile feedback, allowing users to identify, evaluate and appreciate the process of feeling special and wonderful texture. The relationship between redwood furniture and people is not excluded but "symbiotic", is also reflected during the interaction for people and businesses experience. Such as Coomo Furniture used their self-developed, super thin and tough hardware components to achieve the furniture "deformed", this "deformation" approach beyond the general sense of the five sense organ's experience, the diversification of its details to meet people's needs in daily life, a breakthrough innovative method makes the operation and the demand to develop a good feedback experience, which let consumers hooked and attach picture 1 . The owners can show the hidden dynamic features to their family or friends so it can achieve the interactive experience from person to person. When businesses operate the core functions in the furniture presentation, and it is easy to mobilize the customers' emotional perception and deeper interaction.

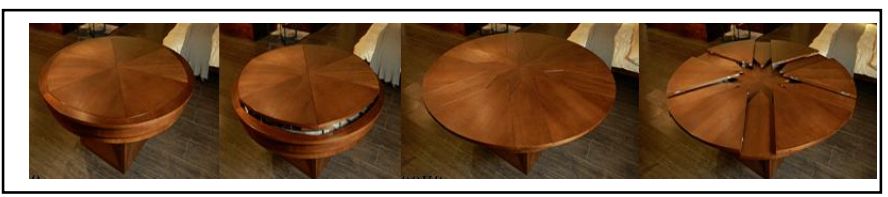

Fig. 1. Coomo "deformation" furniture.

\section{B. Building scenario: Furniture - Space - Culture Experience}

In the past redwood furniture experience, the design was primarily based on furniture's selection, color, craftsmanship, form, construction, comfort and usability. Nowadays designers are beginning to look for the needs beyond material object. It shifts from a single "object" to "thing" or "system". It requires not only creating an enrich experience to promote intimate relationships among family members, but also helping strangers to communicate, understand and promote feelings. redwood furniture experience is the integrated experience of space and culture, and it is also a systematic experience to build a better life scenario. From the cross-industry perspective, we can find the corresponding inspiration and methods. For example, JR East, Japanese passenger transport company developed "Enjoy Time-Varying Train", it integrates furniture design, space design, technical design, architectural design and travel design so that passengers can feel the hotel-like "mobile scenic" experience, in the meanwhile, they can also experience the magnificent and wide nature. So, establishing redwood furniture-space-culture experience, it urgently needs to get rid of the monotonous and boring mode of tourism in traditional redwood museums and create a multi-functional and complex travel model that integrates creation, recreation and culture with science popularization. Each subdivision site should set corresponding theme scenario, lighting, sound effects, decorations, furnishings and so on. These soft surroundings should be created to serve the overall scenario. Therefore, the shaping of space culture should be related to the connotation characteristics of furniture. The product experience and channel experience can not be separated, "manufacturing" and "experiencing" should be closely integrated so that consumers can not only perceive the external formal beauty of redwood furniture experience the craftsmanship spirit which embodied in the design and production process, but also feel our great Chinese cultural and its radiation and influence for people, furniture, space and scenario.

\section{Describing identify:Life - Meaning - Emotional Experience}

Describing identify refers to find the implicit demand of consumers, from the concern about the physical function needs to the life meaning for redwood furniture. Combined with psychologist Maslow's hierarchy of needs, it refers to redwood furniture can meet the needs for people's emotions, sense of belongings and respect. Designers need to create meaningful experiences and gain a deeper understanding among people, furniture, environment, and society these complex relationships in their lives, and strive for creating meaningful and remarkable experiences for others. Drawing from crossfertilization ideas of Gentle monster, the Korean glasses brand, it brings identify experience to the extreme point. The theme space of "Frogism" interprets as the complex emotions of mutual antagonism and mutual attraction between human and animals, and defines the space of glasses for Xanadu as modern people are far away from the stressful and noisy city life. Herman Miller, a top American furniture brand, specialized design office space for "human value." It considers the possibilities of furniture and space from the six standards for human needs: accomplishment, autonomy, belonging, identity, purpose and security. Attach picture 2.Therefore, the identify innovation for traditional Chinese redwood furniture should 
change from the core of designing things to the core of consumer itself, deepen and complete the understanding for consumers' cognition then realize the design will return back to humanity. The specific way is to study all the activities involved in the use of redwood furniture by consumers and expand the meaning of furniture. Then, the chair is seen as a "object" for sitting, the table being understood as an uninterrupted "surface" for placing things, and the space being conceived as a "tool" that accommodates the real thing and realize the meaning of life. So for "object" ,"surfaces" and "tools" can extend more invisible needs, such as discontinuities, transplants, blending, ambition, seclusion, expectation, revival and sharing etc. It will give the furniture products deeper humanistic value demands.

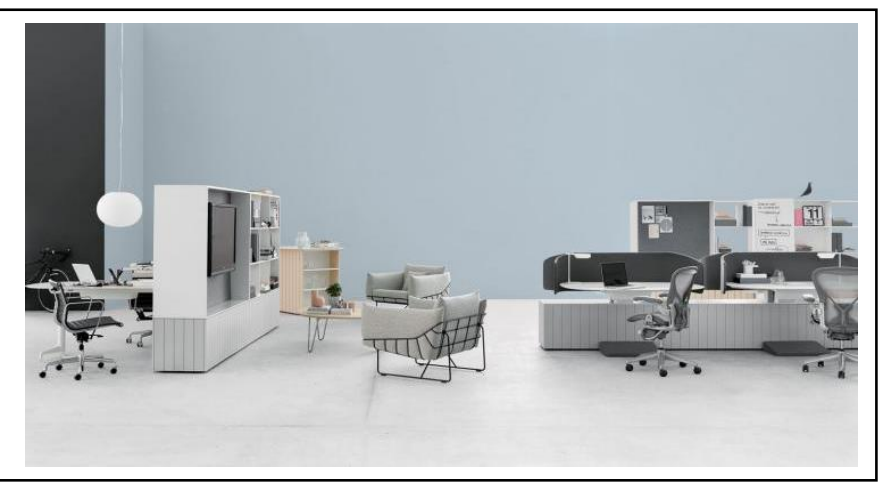

Fig. 2. Herman Miller design the office space based on human value.

\section{The Prospect For Chinese Traditional RedWoOd FURNITURE MANUFACTURING IN 2025}

As advantage traditional manufacturing industry, Chinese redwood furniture should undertake the important mission form "manufacturing" to "intelligent made" and "creation". The purpose for experience design-driven to redwood furniture design innovation, which aims to promote advantage traditional manufacturing industry to seek new design breakthroughs and market opportunities from intelligent experience, green experience, cultural experience, human experience and brand experience. It will have better design to close to human's needs, more extraordinary experience to beyond the user's expectations and bring redwood cultural into more space and filed. In addition, it will offer more true, more pure, more elegant and more cultural value of redwood furniture experience to consumers in the era of "internet plus".

Looking forward the traditional Chinese redwood furniture manufacturing in 2025 , we should stay grounded, but have less impetuous, have more enthusiasm and concentration, but have less flattering and trickery. The connotation of redwood spirit is pursuit for subtle experience which is like "moisten things silently". Only enhancing foundation of design, strengthening manufacturing basis, enhancing the core competitiveness of the brand, can the Chinese redwood furniture have the opportunity of racing with the Top European brands in the same field and at the same step.

\section{REFERENCES}

[1] Lu Jiufang, Redwood furniture heritage and innovation [J]. Journal of Jiangnan University (Humanities and Social Sciences), 2010, 09 (04): 120-124.

[2] Hu Jingchu, Redwood furniture industry restructuring and sustainable development [J]. Furniture and interior decoration, 2012(10): 11-12.

[3] Chinese Academy of Social Sciences Institute of language dictionary editing room, Modern Chinese Dictionary 2002 Supplement [M].Beijing. The Commercial Press, 2003: 976-976.

[4] Han Ji'an, Essence of experience design [J]. Hundred Schools in Arts, 2015 (06): 228-230.

[5] Gu Zhenyu, Interaction design - The theory and method [M]. Beijing: Tsinghua University Press, 2016.

[6] Yan Mei, The design and study for new Chinese style furniture store experience [D]. Central South University of Forestry and Technology, 2014.

[7] Hu Qizhi, WISION furniture: Design innovation blows the horn of "made in China" $[\mathrm{J}]$. Guangdong Industrial Design Communications, 2010 (6): 48-53.

[8] Hu Fei, Asking Design [M]. Beijing: China Architecture \& Building Press, 2011: 112-115. 